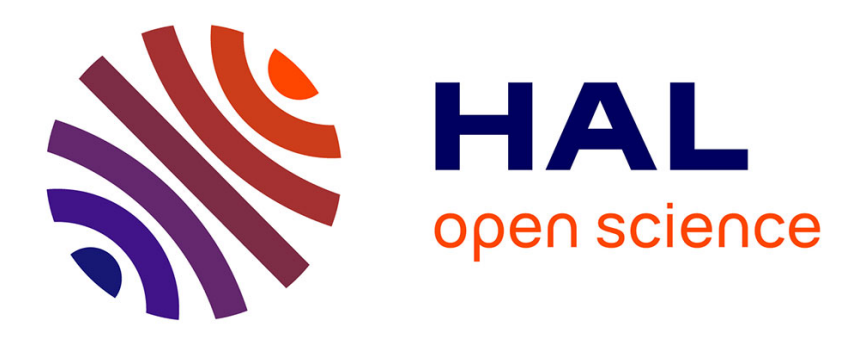

\title{
A note on Marcinkiewicz laws for strictly stationary -mixing sequences
}

\author{
Zbigniew S. Szewczak
}

\section{To cite this version:}

Zbigniew S. Szewczak. A note on Marcinkiewicz laws for strictly stationary -mixing sequences. Statistics and Probability Letters, 2011, 81 (11), pp.1738. 10.1016/j.spl.2011.06.001 . hal-00789867

\section{HAL Id: hal-00789867 https://hal.science/hal-00789867}

Submitted on 19 Feb 2013

HAL is a multi-disciplinary open access archive for the deposit and dissemination of scientific research documents, whether they are published or not. The documents may come from teaching and research institutions in France or abroad, or from public or private research centers.
L'archive ouverte pluridisciplinaire HAL, est destinée au dépôt et à la diffusion de documents scientifiques de niveau recherche, publiés ou non, émanant des établissements d'enseignement et de recherche français ou étrangers, des laboratoires publics ou privés. 


\section{Accepted Manuscript}

A note on Marcinkiewicz laws for strictly stationary $\varphi$-mixing

sequences

Zbigniew S. Szewczak

PII:

S0167-7152(11)00203-3

DOI: $\quad$ 10.1016/j.spl.2011.06.001

Reference: $\quad$ STAPRO 6015

To appear in: Statistics and Probability Letters

Received date: 28 March 2011

Revised date: 31 May 2011

Accepted date: 1 June 2011

Please cite this article as: Szewczak, Z.S., A note on Marcinkiewicz laws for strictly stationary $\varphi$-mixing sequences. Statistics and Probability Letters (2011), doi:10.1016/j.spl.2011.06.001

This is a PDF file of an unedited manuscript that has been accepted for publication. As a service to our customers we are providing this early version of the manuscript. The manuscript will undergo copyediting, typesetting, and review of the resulting proof before it is published in its final form. Please note that during the production process errors may be discovered which could affect the content, and all legal disclaimers that apply to the journal pertain. 


\title{
A note on Marcinkiewicz laws for strictly stationary $\varphi$-mixing sequences
}

\author{
Zbigniew S. Szewczak *
}

30 May 2011

\begin{abstract}
A connection between boundedness in probability and laws of large numbers is established for $\varphi$-mixing strictly stationary sequences.

Key words: Marcinkiewicz-Zygmund law, boundedness in probability, $\varphi-$ mixing, strictly stationary sequences, Ibragimov's conjecture Mathematics Subject Classification (2000): 60F15, 60F05
\end{abstract}

\section{Introduction and results}

Let $\left\{X_{k}\right\}_{k \in \mathbf{Z}}, \mathbf{Z}=\{\ldots,-1,0,1,2, \ldots\}$, be a strictly stationary sequence defined on a probability space $(\Omega, \mathcal{F}, P)$ taking values on the real line $\mathbf{R}$, and $\mathcal{F}_{j}{ }^{k}$ be the $\sigma$-field generated by $X_{j}, X_{j+1}, \ldots, X_{k}, j, k \in \mathbf{Z}, j \leq k$. Set $S_{n}=\sum_{k=1}^{n} X_{k}$, $n \in \mathbf{N}=\{1,2, \ldots\}$ and define

$$
\varphi_{n}=\sup \left\{|P(B \mid A)-P(B)| ; P(A)>0, A \in \mathcal{F}_{-\infty}^{0}, B \in \mathcal{F}_{n}^{\infty}\right\} .
$$

If $\lim _{n \rightarrow \infty} \varphi_{n}=0$, then $\left\{X_{k}\right\}$ is said to be uniformly strong mixing or $\varphi$-mixing.

The main purpose of this note is to shed some light on the connection between boundedness in probability and laws of large numbers for dependent random variables. Recall that a sequence $\left\{Y_{n}\right\}$ is bounded in probability (b.i.p.) or stochastically bounded, if for each $\epsilon>0$ one can find $M>0$ with $\sup _{n} P\left[\left|Y_{n}\right|>M\right]<\epsilon$. Our first result states the Marcinkiewicz-Zygmund law in terms of b.i.p. (cf. Marcinkiewicz and Zygmund, 1937, Théorème 9).

Theorem 1 Suppose $r \in(1,2)$ is a real number and $\left\{X_{k}\right\}$ is a strictly stationary $\varphi-$ mixing sequence. Then $n^{-\frac{1}{r}} S_{n} \rightarrow 0$ almost surely iff $\left\{n^{-\frac{1}{r}} S_{n}\right\}$ is b.i.p. and $E\left[\left|X_{1}\right|^{r}\right]<\infty$.

If moments do not exist, our next theorem gives a similar characterization (see also Szewczak, 2010, Theorem 1, Theorem 2 and Remark 14). Define

$$
c_{n}=c_{n}(r)=\sup \left\{x>0 ; x^{-r} E\left[\left|X_{1}\right|^{r} I_{\left[\left|X_{1}\right| \leq x\right]}\right] \geq \frac{1}{n}\right\} .
$$

Since $x^{-r} E\left[\left|X_{1}\right|^{r} I_{\left[\left|X_{1}\right| \leq x\right]}\right] \rightarrow 0$ as $x \rightarrow \infty$, thus $c_{n}$ is finite and by Lemma 7 in Szewczak (2010) $n E\left[\left|X_{1}\right|^{r} I_{\left[\left|X_{1}\right| \leq c_{n}\right]}\right] \sim c_{n}^{r}$.

\footnotetext{
${ }^{*}$ Nicolaus Copernicus University, Faculty of Mathematics and Computer Science, ul. Chopina 12/18, 87-100 Toruń, Poland, e-mail: zssz@mat.uni.torun.pl
} 
Theorem 2 Suppose $\left\{X_{k}\right\}$ is a strictly stationary $\varphi$-mixing sequence and $E\left[\left|X_{1}\right|^{r}\right]=\infty$ for some real $r \in(1,2)$. If $\left\{c_{n}^{-1} S_{n}\right\}$ is b.i.p. and $E\left[\left|X_{1}\right|^{r} I_{\left[\left|X_{1}\right| \leq x\right]}\right]$ is slowly varying in the sense of Karamata, then $c_{n}^{-1} S_{n} \rightarrow 0$ in probability. Conversely, if $c_{n}^{-1} S_{n} \rightarrow 0$ in probability and $\varphi_{1}<1$, then $E\left[\left|X_{1}\right|^{r} I_{\left[\left|X_{1}\right| \leq x\right]}\right]$ is slowly varying and $E\left[X_{1}\right]=0$.

For $\left\{X_{k}\right\}$ independent and identically distributed (i.i.d.) with $E\left[\left|X_{1}\right|^{r} I_{\left[\left|X_{1}\right| \leq x\right]}\right]$ slowly varying, $r \in(1,2],\left\{c_{n}^{-1} S_{n}\right\}$ is b.i.p. iff $E\left[X_{1}\right]=0$ (see Remark 1 and Lemma 2). In the case of sums of dependent random variables a tool for verifying b.i.p. is von Bahr-Esseen's inequality (cf. Bahr and Esseen, 1965, Theorem 2). Namely, if $\left\{X_{k}\right\}$ is (not necessarily stationary) random sequence such that $E\left[\left|X_{k}\right|^{r}\right]<\infty, k=1, \ldots, n$, and $E\left[X_{m+1} \mid S_{m}\right]=0$ a.s., $m \in \mathbf{N}$, $1 \leq m \leq n-1,1 \leq r \leq 2$, then $E\left[\left|\sum_{k=1}^{n} X_{k}\right|^{r}\right] \leq 2 \sum_{k=1}^{n} E\left[\left|X_{k}\right|^{r}\right]$. Note that the case $r=2$, related to the Central Limit Theorem (CLT), is also included here. Another approach is the use of the truncation method together with the convergence rate of $\varphi_{n}$ coefficients (cf. Szewczak, 2011, Corollary 1). Yet another inequality of interest is stated in Lemma 8.22 on p. 268 in Bradley, 2007, vol. I (see Remark 1). Unfortunately in our setting it is unknown if $\left\{c_{n}^{-1} S_{n}\right\}$ is b.i.p. or $n^{-1} \sup _{n} E\left[\left|S_{n}-E\left[S_{n}\right]\right|^{r}\right]<\infty, r \in(1,2]$, (cf. Bradley, 2007, vol. III, P2 Question, p. 457). This situation corresponds to the still unsolved Ibragimov's conjecture (cf. Bradley, 2007, vol. III, P1 Ibragimov's Conjecture, p. 457) and Iosifescu-Peligrad's conjecture (cf. Bradley, 2007, vol. III, P3 Iosifescu's Conjecture, p. 457; Peligrad, 1990, Conjecture 1.3) related to the CLT and its invariance principle, respectively. Therefore it is natural to state the following conjecture, this time related to Marcinkiewicz laws of large numbers (see Lemma 2).

Conjecture 1 Suppose $\left\{X_{k}\right\}$ is a stationary random sequence which is $\varphi$ mixing and $E\left[\left|X_{1}\right|^{r} I_{\left[\left|X_{1}\right| \leq x\right]}\right], r \in(1,2]$, varies slowly. If $E\left[X_{1}\right]=0$ then, $\left\{c_{n}^{-1} S_{n}\right\}$ is b.i.p.

Remark 1 It is worth noting that under condition $\lim _{n} q_{n}^{*}<1$ Conjecture 1 holds. Recall the definition of coefficient $q_{n}^{*}$ (cf. Bradley, 2007, vol. I, p. 249)

$$
q_{n}^{*}=\sup \frac{E\left[\left(\sum_{j \in Q} X_{j}\right)\left(\sum_{k \in S} X_{k}\right)\right]}{\left\|\left(\sum_{j \in Q} X_{j}\right)\right\|_{2} \cdot\left\|\left(\sum_{k \in S} X_{k}\right)\right\|_{2}},
$$

where this sup is taken over all pairs of nonempty, disjoint, finite sets $Q, S \subset \mathbf{Z}$ such that $\inf _{j \in Q, k \in S}|j-k| \geq n$ and $\|\cdot\|_{2}$ is $L^{2}$ norm. Since $E\left[\left|X_{1}\right|^{r} I_{\left[\left|X_{1}\right| \leq x\right]}\right]$ varies slowly, $\frac{x^{r-1} E\left[\left|X_{1}\right| I_{\left[\left|X_{1}\right|>x\right]}\right]}{E\left[\left|X_{1}\right|^{r} I_{\left[\left|X_{1}\right| \leq x\right]}\right]} \rightarrow 0$ as $x \rightarrow \infty$ (cf. Feller, 1971, Theorem 2, p. 283) therefore

$$
\lim _{n} n c_{n}^{-1} E\left[\left|X_{1}\right| I_{\left[\left|X_{1}\right|>c_{n}\right]}\right]=\lim _{n} \frac{n c_{n}^{-1} E\left[\left|X_{1}\right| I_{\left[\left|X_{1}\right|>c_{n}\right]}\right]}{\frac{n}{c_{n}^{r}} E\left[\left|X_{1}\right|^{r} I_{\left[\left|X_{1}\right| \leq c_{n}\right]}\right]}=0 .
$$

On the other hand by Lemma 8.22 on p. 268 in Bradley (2007), vol. I

$$
c_{n}^{-2} E\left[\left(\sum_{k=1}^{n} X_{k} I_{\left[\left|X_{k}\right| \leq c_{n}\right]}-E\left[X_{k} I_{\left[\left|X_{k}\right| \leq c_{n}\right]}\right]\right)^{2}\right]
$$




$$
\leq 4 m \frac{1+q_{m}^{*}}{1-q_{m}^{*}} \frac{n}{c_{n}^{2}} E\left[X_{1}^{2} I_{\left[\left|X_{1}\right| \leq c_{n}\right]}\right] \leq 4 m \frac{1+q_{m}^{*}}{1-q_{m}^{*}} \frac{n}{c_{n}^{r}} E\left[\left|X_{1}\right|^{r} I_{\left[\left|X_{1}\right| \leq c_{n}\right]}\right],
$$

for $m$ such that $q_{m}^{*}<1$ and $n>m$. Since $\frac{n}{c_{n}^{r}} E\left[\left|X_{1}\right|^{r} I_{\left[\left|X_{1}\right| \leq c_{n}\right]}\right]$ is bounded therefore $\left\{c_{n}^{-1} S_{n}\right\}$ is b.i.p. by the Chebyshev inequality and the truncation argument. Thus if Bradley's conjecture (cf. Bradley, 2007, vol. III, P10 Conjecture, p. 461) turns out to be true, then Conjecture 1 would follow.

The note is organized in such a way that in Section 2 there are some auxiliary inequalities required for the proofs in Section 3.

\section{Auxiliary inequalities}

Let $\left\{X_{k}\right\}$ be a (not necessarily strictly stationary) random sequence and $n>m$, $i \in \mathbf{N}, p, s, t, u>0$. Recall the following extension of the Hoffmann-Jørgensen inequality from Szewczak (2010).

$$
\begin{aligned}
P\left[\max _{1 \leq k \leq n}\left|S_{k}\right|>s+2 t\right. & \left.+u ; m \cdot \max _{1 \leq i \leq n}\left|X_{i}\right| \leq u\right] \\
& \leq\left(\varphi_{m}+P\left[\max _{m \leq k \leq n}\left|S_{k}\right|>s\right]\right) \cdot P\left[\max _{1 \leq k \leq n-m}\left|S_{k}\right|>t\right]
\end{aligned}
$$

where $\varphi_{m}=\sup _{k \in \mathbf{Z}}\left\{|P(B \mid A)-P(B)| ; A \in \mathcal{F}_{-\infty}^{k}, B \in \mathcal{F}_{k+m}^{\infty}\right\}$. Similarly, in Szewczak (2010) we gave a dependent version of Lévy's inequality (cf. Marcinkiewicz, 1939, Théorème 3$)$, if the laws of reversed sums $\mathcal{L}\left(S_{n}-S_{k}\right)$ are symmetric for $n>k \geq 1$

$$
\left(\frac{1}{2}-\varphi_{m}\right) \cdot P\left[\max _{1 \leq k \leq n-m+1}\left|S_{n}\right|>t\right] \leq P\left[\left|S_{n}\right|+(m-1) \cdot \max _{1 \leq i \leq n}\left|X_{i}\right|>t\right] .
$$

The following moment inequality can be derived from (2.1)(cf. Szewczak, 2010)

$$
E\left[\max _{1 \leq k \leq n}\left|S_{k}\right|^{p}\right] \leq \frac{4^{p}}{1-\tau} \cdot\left(m^{p} E\left[\max _{1 \leq i \leq n}\left|X_{i}\right|^{p}\right]+t_{\tau}^{p}\right)
$$

where

$$
t_{\tau}=\inf \left\{t>0 ; \varphi_{m}+P\left[\max _{m \leq k \leq n}\left|S_{k}\right|>t\right] \leq \frac{\tau}{4^{p}}\right\}, \quad \tau \in(0,1) .
$$

Since inequalities (2.1), (2.2) and (2.3) include the term $M_{n}=\max _{1 \leq i \leq n}\left|X_{i}\right|$ the following inequality for strictly stationary sequence $\left\{X_{k}\right\}$ is useful because it allows replacing dependent maxima satisfying Doeblin's condition (i.e. $\varphi_{m}<1$ ) by the maxima of its associated sequence $\left\{X_{k}^{*}\right\}$ (i.e. the i.i.d. sequence with $\left.\mathcal{L}\left(X_{1}\right)=\mathcal{L}\left(X_{1}^{*}\right)\right)$ :

$$
\left(1-\varphi_{m}\right) \cdot P\left[M_{\left\lfloor\frac{n}{m}\right\rfloor}^{*}>t\right] \leq P\left[M_{n}>t\right] \leq m \cdot\left(1+\varphi_{m}\right) \cdot P\left[M_{\left\lfloor\frac{n}{m}\right\rfloor+1}^{*}>t\right], t \geq 0, n \geq 1,
$$

where $M_{n}^{*}=\max _{1 \leq i \leq n}\left|X_{i}^{*}\right|$ (cf. Peligrad, 1990, p. 298). Recall also von Bahr-Esseen's symmetrization inequality (cf. Bahr and Esseen, 1965, Lemma 4)

$$
\frac{1}{2} E\left[|\widehat{X}|^{r}\right] \leq E\left[|X-E[X]|^{r}\right] \leq E\left[|\widehat{X}|^{r}\right], \quad r \in[1,2],
$$

where $\widehat{X}=X-\tilde{X}$ and $\tilde{X}$ is an independent copy of $X$. 


\section{Proofs}

Theorems 1 and 2 are implied respectively by Theorem 1 in Szewczak (2011), as well as Theorem 1 and 2 in Szewczak (2010) and the following two lemmas (cf. Szewczak, 2010, Remark 14).

Lemma 1 Suppose $\left\{X_{k}\right\}$ is a strictly stationary $\varphi$-mixing sequence, $r \in(1,2]$ and $E\left[\left|X_{1}\right|^{r} I_{\left[\left|X_{1}\right| \leq x\right]}\right]$ varies slowly. If $\left\{c_{n}^{-1} S_{n}\right\}$ is b.i.p. then,

$$
\sup _{n} c_{n}^{-r} E\left[\left|\sum_{k=1}^{n}\left(X_{k} I_{\left[\left|X_{k}\right| \leq c_{n}\right]}-E\left[X_{1} I_{\left[\left|X_{1}\right| \leq c_{n}\right]}\right]\right)\right|^{r}\right]<\infty .
$$

\section{Proof OF LEMMA 1}

Set $S_{n}^{\prime}=\sum_{k=1}^{n} X_{k} I_{\left[\left|X_{k}\right| \leq c_{n}\right]}$. Since $E\left[\left|X_{1}\right|^{r} I_{\left[\left|X_{1}\right| \leq x\right]}\right]$ varies slowly, thus we have $n P\left[\left|X_{1}\right|>\epsilon c_{n}\right] \rightarrow 0, \epsilon>0$ (cf. Feller, 1971, Theorem 2, p. 283). Hence

$$
c_{n}^{-1} \max _{1 \leq i \leq n}\left|X_{i}\right| \rightarrow 0, \quad \text { in probability. }
$$

Therefore $\left\{c_{n}^{-1} S_{n}^{\prime}\right\}$ is b.i.p. Set $\widehat{S_{n}^{\prime}}=\sum_{k=1}^{n} X_{k} I_{\left[\left|X_{k}\right| \leq c_{n}\right]}-\tilde{X}_{k} I_{\left[\left|\tilde{X}_{k}\right| \leq c_{n}\right]}$, where $\left\{\tilde{X}_{k}\right\}$ is an independent copy of $\left\{X_{k}\right\}$. Hence $\left\{c_{n}^{-1} \widehat{S_{n}^{\prime}}\right\}$ is b.i.p. too. Choose $m$ such that $\varphi_{m}<1-\frac{1}{\sqrt{2}}$ so that $\widehat{\varphi}_{1}=\varphi_{1}\left(\left\{\widehat{X}_{k}\right\}\right)<\frac{1}{2}$ (cf. Bradley, 2007, vol. I, Theorem 6.6, p.199). Now (2.2) and (3.7) yield that $\left\{\max _{1 \leq k \leq n} c_{n}^{-1}\left|\widehat{S_{k}^{\prime}}\right|\right\}$ is b.i.p. Moreover, by (2.4)

$$
\varlimsup_{n} c_{n}^{-r} E\left[\max _{1 \leq i \leq n}\left|X_{i}\right|^{r} I_{\left[\left|X_{i}\right| \leq c_{n}\right]}\right] \leq 2 m \varlimsup_{n}\left\lfloor\frac{n}{m}\right\rfloor c_{n}^{-r} E\left[\left|X_{1}\right|^{r} I_{\left[\left|X_{1}\right| \leq c_{n}\right]}\right] \leq 2
$$

thus

$$
\sup _{n} c_{n}^{-r} E\left[\max _{1 \leq i \leq n}\left|X_{i} I_{\left[\left|X_{i}\right| \leq c_{n}\right]}-\tilde{X}_{i} I_{\left[\left|\tilde{X}_{i}\right| \leq c_{n}\right]}\right|^{r}\right]<\infty .
$$

Therefore by (2.3) we get $E\left[\max _{1 \leq k \leq n} c_{n}^{-r}\left|{\widehat{S_{k}^{\prime}}}^{\prime}\right|^{r}\right]<C$ for some $C<\infty$ and every $n \in \mathbf{N}$. Consequently, condition (3.6) follows from (2.5). This completes the proof.

It is interesting that the converse of Conjecture 1 holds.

Lemma 2 Suppose $\left\{X_{k}\right\}$ is a strictly stationary $\varphi$-mixing sequence, $r \in(1,2]$ and $E\left[\left|X_{1}\right|^{r} I_{\left[\left|X_{1}\right| \leq x\right]}\right]$ varies slowly. If $\left\{c_{n}^{-1} S_{n}\right\}$ is b.i.p., then $E\left[X_{1}\right]=0$.

Proof of Lemma 2

Since $r>1$, and $E\left[\left|X_{1}\right|^{r} I_{\left[\left|X_{1}\right| \leq x\right]}\right]$ varies slowly, thus $E\left|X_{1}\right|<\infty$. By the proof of Lemma 1 we see that $\left\{c_{n}^{-1} S_{n}^{\prime}\right\}$ is b.i.p. Moreover, by the Markov inequality and (3.6), the sequence $\left\{c_{n}^{-1}\left(S_{n}^{\prime}-n E\left[X_{1} I_{\left[\left|X_{1}\right| \leq c_{n}\right]}\right]\right)\right\}$ is also b.i.p. so that $\left\{c_{n}^{-1} n E\left[X_{1} I_{\left[\left|X_{1}\right| \leq c_{n}\right]}\right]\right\}$ is b.i.p. too. Furthermore, by a variant of Karamata's theorem (cf. Feller, 1971, Theorem 2, p. 283)

$$
c_{n}^{r-1} \frac{E\left[\left|X_{1}\right| I_{\left[\left|X_{1}\right|>c_{n}\right]}\right]}{E\left[\left|X_{1}\right|^{r} I_{\left[\left|X_{1}\right| \leq c_{n}\right]}\right]} \rightarrow 0 \quad \text { as } n \rightarrow \infty .
$$


Since $n E\left[\left|X_{1}\right|^{r} I_{\left[\left|X_{1}\right| \leq c_{n}\right]}\right] \sim c_{n}^{r}$, thus (3.8) yields

$$
c_{n}^{-1} n E\left[\left|X_{1}\right| I_{\left[\left|X_{1}\right|>c_{n}\right]}\right] \rightarrow 0 \quad \text { as } \quad n \rightarrow \infty .
$$

Therefore $\left\{c_{n}^{-1} n\left|E\left[X_{1}\right]\right|\right\}$ is a bounded sequence. On the other hand the slow variation of $E\left[\left|X_{1}\right|^{r} I_{\left[\left|X_{1}\right| \leq x\right]}\right]$ entails

$$
c_{n}^{r} n^{-r} \sim n^{1-r} E\left[\left|X_{1}\right|^{r} I_{\left[\left|X_{1}\right| \leq c_{n}\right]}\right] \rightarrow 0 \quad \text { as } n \rightarrow \infty .
$$

Thus the only possibility is $E\left[X_{1}\right]=0$ and Lemma 2 follows.

Acknowledgement. The author thanks the anonymous referee and Andrzej Szewczak for constructive remarks and suggestions that improved the presentation of the paper.

\section{References}

Bahr, B. von, Esseen, C.-G., 1965. Inequalities for the $r$-th absolute moment of a sum of random variables $1 \leq r \leq 2$. Ann. Math. Stat. 36, 299-303.

Bradley, R. C., 2007. Introduction to Strong Mixing Conditions. Vol. I-III, Kendrick Press.

Feller, W., 1971. An Introduction to Probability Theory and Its Applications. vol. II 2nd ed., Wiley, New York.

Marcinkiewicz, J., Zygmund, A., 1937. Sur les fonctions indépendantes. Fund. Math. 29, 60-90.

Marcinkiewicz, J., 1939. Quelques théorèmes de la théorie des probabilités. Bull. Sém. Math. Univ. Wilno 2, 22-34 (reprinted in: J. Marcinkiewicz, Collected Papers, A. Zygmund (ed.), PWN, Warszawa, 1964, pp. 566-579).

Peligrad, M., 1990. On Ibragimov-Iosifescu conjecture for $\varphi$-mixing sequences. Stochastic Process. Appl. 35, 293-308.

Szewczak, Z. S., 2010. Marcinkiewicz laws with infinite moments. Acta Math. Hungar. 127, 64-84.

Szewczak, Z. S., 2011. On Marcinkiewicz-Zygmund laws. J. Math. Anal. Appl. 375, 738-744. 